\title{
FOUCAULT IN/MORALISTA
}

\author{
MIGUEL MOREY FARRÉ \\ Universidad de Barcelona
}

\begin{abstract}
RESUMEN: 1975 es el año en el que, con la publicación de Vigilar y castigar, Foucault propone un modelo de análisis microfísico del poder que viene a desplazar gravemente los análisis políticos habituales; también es éste el año en el que, en España, la muerte del dictador Franco va a acarrear cambios políticos cruciales, como es sabido. La recepción de estos análisis en nuestro país, antes que en las aulas de las facultades de Filosofía, corrió primeramente a cargo de otros grupos universitarios de trabajo (arquitectos, pedagogos, psicólogos, psicoanalistas y psiquiatras, juristas...), y también por algunos movimientos sociales de carácter alternativo. En los encuentros de trabajo que tuvieron lugar con varios de estos grupos, las dificultades que bloqueaban la correcta inteligibilidad de su trabajo eran muy diversas. Es en este contexto que surge la figura del in/moralista, como una vía de acceso al conjunto de gestos elementales en los que su discurso se sustenta.
\end{abstract}

PALABRAS CLAVE: diagnóstico del presente; intelectual universal / intelectual específico; aprobación/ desaprobación; rechazo - curiosidad - innovación; transgresión; creación de libertad.

\section{In/moralist Foucault}

ABSTRACT: 1975 is the year in which, with the publication of Surveiller et punir, Foucault proposes a model of microphysical analysis of power that seriously displaces the usual political analyses; this is also the year in which, in Spain, the death of dictator Franco will bring about crucial political changes, as is well known. The reception of these analyses in our country, rather than in the classrooms of the Faculties of Philosophy, was firstly carried out by other university work groups (architects, pedagogues, psychologists, psychoanalysts and psychiatrists, jurists...), and also by some alternative social movements. In the work encounters that took place with several of these groups, the difficulties that blocked the correct intelligibility of their work were very diverse. It is in this context that the figure of the in/moralist emerges, as a way of access to the set of elementary gestures on which his discourse is based.

KEY WORDS: Diagnosis of the present; universal intellectual / specific intellectual; approval/ disapproval; refusal - curiosity - innovation; transgression; creation of freedom.

In a sense, I am a moralist, insofar as I believe that one of the tasks, one of the meanings of human existence-the source of human freedom-is never to accept anything as definitive, untouchable, obvious, or immobile. No aspect of reality should be allowed to become a definitive and inhuman law for us. We have to rise up against all forms of power-but not just power in the narrow sense of the word, referring to the power of a government or of one social group over another: these are only a few particular instances of power. Power is anything 
that tends to render immobile and untouchable those things that are offered to us as real, as true, as good.

Michel Foucault, «Power, Moral Values, and the Intellectual» (1980)1.

Quisiera proponer una figura del pensamiento de Foucault en cierto modo arcaica, por tosca, por elemental, pero que podría tener también el sentido de embrión primero o foco genético, o que tal vez se corresponda con el estrato verbal más primario de su pensamiento, en el que se juega con las afirmaciones más elementales. Presento la figura nombrándola «in/moralista», con una barra que espacia la negación, no por ninguna coquetería semiologicista, sino para señalar la zona de vecindad indecidible, de negación en suspenso, de reversión siempre posible de cada uno de los polos sobre el otro, como el espacio de encuentro entre el agua dulce y el agua salada que se forma en los deltas. Un espacio al que, por otra parte, los aforismos de Nietzsche ya han hecho que nos acostumbremos...

Esta figura tiene una historia, es el resultado de un primer encuentro que tuvo lugar hace unos cuarenta años, con ocasión de la primera gran recepción que hubo en España de la obra de Foucault. En el año 1978, se publican: Microfísica del poder, editado por Julia Varela y Fernando Álvarez-Uría, y mi selección de entrevistas Sexo, verdad, poder, con un prólogo de 60 páginas, que proponía una presentación general del trabajo de Foucault² ${ }^{2}$ La atención universitaria,

1 «En cierto sentido, soy un moralista, en la medida en que creo que una de las tareas, uno de los significados de la existencia humana - la fuente de la libertad humana- es no aceptar nunca nada como definitivo, intocable, obvio o inmóvil. No se debe permitir que ningún aspecto de la realidad se convierta en una ley definitiva e inhumana para nosotros. Tenemos que levantarnos contra todas las formas de poder - pero no sólo contra el poder en el sentido estricto de la palabra, refiriéndonos al poder de un gobierno o de un grupo social sobre otro: estos son sólo unos pocos casos particulares de poder. El poder es cualquier cosa que tienda a convertir en inmóviles e intocables aquellas cosas que se nos presentan como reales, como verdaderas, como buenas». Foucault, M., «Power, Moral Values, and the Intellectual», entrevista con Michael Bess (3 de noviembre de 1980), en: History of the Present, $\mathrm{n}^{\circ}$ 4, primavera 1988, pp. 1-2, 11-13.

2 Microfísica del poder, ediciones la Piqueta, Madrid 1978; recogía, además del texto «Nietzsche, la genealogía, la historia», una selección de entrevistas (de 1971 a 1977), más la transcripción de dos clases de Foucault en el Collège de France, de enero de 1976, correspondientes al curso "Il faut défendre la société». El contenido es el mismo que la selección italiana de Alessandro Fontana y Pasquale Pasouino, Microfisica del potere: interventi politici (Einaudi, Turín 1977), con el añadido de una entrevista que no figura en el original italiano: «Poderes y estrategias» (respuesta a un cuestionario de la revista Les révoltes logiques, 1977; cfr. Foucault, M., Dits et écrits [en adelante DE], III, § 218), y «Verdad y poder» (entrevista con A. Fontana, publicada en L'Arc, en 1977, que formaba parte de la larga entrevista que sirve de introducción a la citada edición italiana; cfr. Foucault, M., DE III, § 192). Por su parte, Sexo, Verdad, Poder recogía siete entrevistas sobre la cuestión del poder (tres del post-mayo del 68, y cuatro de 1977, posteriores por tanto a la publicación de Vigilar y castigar, y al desplazamiento que supuso su proyecto de una historia de la sexualidad, con la aparición de $L a$ voluntad de saber); se publicó originalmente en la editorial Materiales (Barcelona 1978), y se reeditó en Alianza editorial en 1981, con el titulo de Michel Foucault: un diálogo sobre el poder, 
académica a una posible recepción del pensamiento de Foucault tuvo su momento alrededor de 1968 (fecha de la traducción al español de Las palabras y las cosas), y la respuesta fue por lo general negativa, hasta el punto de crearse un cierto consenso según el cual era dudoso que lo que Foucault hacía tuviera algo que ver con la filosofía. Hubo sus excepciones naturalmente, como el ejemplo de Eugenio Trías muestra de modo bien contundente ${ }^{3}$, pero fueron literalmente excepcionales. Sin embargo, se recordará que en 1975 había muerto Franco, dando lugar a la encrucijada política consiguiente, y que ese mismo año Foucault publicaba Vigilar castigar, texto en el que hacía su presentación en público una propuesta de comprensión microfísica de lo político. La recepción de finales de los años setenta era pues completamente otra, sus condiciones habían cambiado por entero, el contexto era muy diferente (a finales de aquel año, en España, iba a aprobarse la Constitución) y la obra del mismo Foucault había dado un giro espectacular.

Sin embargo, antes que en las aulas de las facultades de Filosofía, el trabajo reciente de Foucault fue recibido por otros grupos universitarios de trabajo (arquitectos, pedagogos, psicólogos, psicoanalistas y psiquiatras, juristas...), y también por algunos movimientos sociales de carácter alternativo; así, fue bien acogido en los Ateneos populares y/o libertarios que empezaban a proliferar y en algunos colectivos de gays y lesbianas, como se llamaban entonces. Este desplazamiento en la atención prestada al pensamiento de Foucault es congruente con la distinción que en aquellos momentos el propio Foucault estaba promoviendo entre «intelectual universal» e «intelectual específico» ${ }^{4}$. Así, de un

con una nueva presentación y aligerado de su larga introducción original, y otra vez en la misma editorial en 2001, con una introducción nueva en la que se pormenorizan las circunstancias de nacimiento del libro.

3 Me remito en particular a La filosofía y su sombra (Seix Barral Ed., Barcelona 1969), especialmente a su tercera parte, «La filosofía sin el hombre»; y a la primera y segunda parte de Filosofía y carnaval (Ed. Anagrama, Barcelona 1973): «El loco tiene la palabra» y «Arqueología de la cultura occidental». Pero hay que recordar que, en aquellas fechas, la relevancia académica de Eugenio Trías no iba más allá de ser una «joven promesa», y bastante controvertida además.

4 Se recordará: «Admitamos la importancia tomada por el intelectual especifico con el desarrollo de las estructuras técnico-científicas en la sociedad contemporánea, desde hace unas décadas, y la aceleración de este movimiento desde 1960. El intelectual específico se encuentra con obstáculos y se expone a unos peligros. Peligro de quedar inmerso en luchas de coyuntura, en reivindicaciones sectoriales. Riesgo de dejarse manipular por los partidos políticos o por los aparatos sindicales que conducen estas luchas locales. Riesgo sobre todo de no poder desarrollar estas luchas por falta de una estrategia global y de apoyos exteriores. Riesgo también de no ser seguido o de serlo solamente por grupos muy limitados. Me parece que estamos en un momento en el que la función del intelectual específico debe ser reelaborada. No abandonada, a pesar de la nostalgia de algunos por los grandes intelectuales "universales" ("necesitamos —se dice— una filosofía, una visión del mundo"); basta con pensar en los resultados importantes obtenidos en psiquiatría: prueban que estas luchas locales y especificas no han sido un error y no han conducido a ningún impasse. Puede incluso decirse que el papel del intelectual especifico debe ser cada vez mas importante, a la medida de las responsabilidades políticas que por las buenas o por las malas está obligado asumir en tanto que físico atómico, genetista, técnico en informática, farmacologista, etcétera». Véase 
modo rápido, podría decirse que el último trabajo de Foucault fue recibido con atención e interés por aquellos sectores comprometidos con un ámbito social específico (la salud, la educación, la penalidad...), cuyas luchas políticas tenían un carácter fuertemente local y para las que carecía de relevancia la cuestión de si Foucault era o no un filósofo, y cuál era el estatuto teórico de sus discursos... En cambio, estas cuestiones eran precisamente las previas y las prioritarias, las que condicionaban la posibilidad de cualquier tipo de recepción desde el punto de vista del «intelectual universal», que era la perspectiva adoptada por la filosofía institucional.

En ese contexto, está claro que, cuando se reclamaba la intervención de quienes estábamos más familiarizados con el pensamiento de Foucault, lo que se solicitaba de nosotros no era una exposición meramente profesoral, según las hechuras académicas al uso. De lo que se trataba era de traducir a lenguaje ordinario aquellos aspectos de su pensamiento que les pudieran resultar más interesantes como colectivo (es decir, más útiles para el pensamiento y la acción de acuerdo con sus intereses). Y en el buen entendido de que no existía doctrina ninguna sobre la problemática propia a cada uno de esos colectivos en la obra de Foucault, y sí en no pocos casos, una retahíla de argumentos para alimentar la mala conciencia gremial de una buena parte de dichos colectivos.

Si se tratara de encontrar un común denominador del que participaran todas aquellas demandas de colectivos tan dispares, forzosamente habría que ampliar de modo considerable su nivel de generalidad, hasta situarnos en el plano de lo que podríamos llamar cuestiones entitativas, que remitirían al estatuto de cada opción profesional o vital, a su relación con unas formas de saber establecido y con el ejercicio de ese saber en un medio institucional determinado. Y la primera demanda adoptaría la forma de una interrogación por el juego aprobación/desaprobación que Foucault ponía en obra en sus análisis de problemas cercanos a los propios al colectivo en cuestión. Y se hacía así con la esperanza de que una cierta familiaridad con los modos de aprobación/desaprobación del discurso foucaultiano y con algunos de los argumentos y contraargumentos que los sostenían, pudiera funcionar como una primera forma de orientación, un modo de abrir un croquis de trayectos con el que ir urdiendo una cartografía en el que la propia problemática pudiera irse integrando. Con las correcciones de rigor, encontraríamos la misma dinámica también en los colectivos alternativos. En ambos casos, muy a menudo, esta primera demanda se doblaba irremediablemente con la pregunta por su posición política: el pensamiento de Foucault, ¿era de izquierdas o de derechas? Podría decirse que en el intento de centrar este par de cuestiones es como se fue formando la figura de lo que aquí se llama in/moralista ${ }^{5}$.

Foucault, M., «Verdad y Poder. Diálogo con M. Fontana», trad. M. M., recogido en: Un diálogo sobre el poder.

5 Sin duda hubiera sido de mucha ayuda en su momento disponer del documento que se cita en el lema del presente texto, dado que en él Foucault parece sentar explícitamente los puntos de apoyo últimos de su gesto de pensamiento, y dar respuesta así a las primeras 
Hay que añadir que, desde esta figura, la cuestión política era relativamente sencilla de contestar (aunque pudiera hacerse interminable), o tal vez mejor, de soslayar... Y es que, en principio, su pensamiento no necesita ser de izquierdas ni de derechas para proceder según el modo en que procede, le basta con ser profunda, radicalmente republicano. Y aquí imaginar el ejemplo de Sade, leído y puesto a prueba por Georges Bataille se hace inevitable ${ }^{6}$. En cuanto al par aprobación/desaprobación, he de confesar la probable intromisión en su gestación de M. Detienne y sus Maestros de la verdad en la Grecia arcaica publicado por entonces ${ }^{7}$, porque el dispositivo básico con el que se me construía la figura del in/moralista aparecía a la sombra del par con el que los poetas ejercían como maestros arcaicos de la verdad (en la cultura oral), el ह̌ं $\alpha$ avo alabanza y la censura.

Lo curioso del caso vendrá luego, al comprobar que esta figura arcaica del juego de lo verdadero y lo falso que aparece a petición de una serie de auditorios precisos, se encuentra presente de modo manifiesto y repetido a lo largo de toda la obra de Foucault, con una notoriedad muy destacable en sus intervenciones orales, en debates y entrevistas. $Y$ en cualquier caso, constituye siempre una franja verbal, un registro de enunciación que está de continuo inmiscuido en su discurso, pautándolo a veces, cerrándolo en otras ocasiones... Hasta el punto de que si se frecuenta la obra de Foucault es inevitable acabar reconociendo los momentos en los que Foucault parece construir ese interlocutor de manera explícita - momentos en los que parece interpelar al lector en esa zona de su soledad lectora en la que se toman decisiones en términos de aprobación o desacuerdo.

demandas de entonces. (Y aprovecho para recordar que, en los momentos de los que se está hablando, ni el corpus ni la recepción del pensamiento de Foucault tenía ni por asomo las proporciones actuales.) Dice allí: «Antes estaba hablando de los tres elementos de mi moral. Son (1) la negativa a aceptar como evidentes las cosas que se nos proponen; (2) la necesidad de analizar y conocer, ya que no podemos lograr nada sin reflexión y comprensión —así, el principio de la curiosidad; y (3) el principio de la innovación: buscar en nuestra reflexión aquello que nunca se ha pensado o imaginado. Así: el rechazo, la curiosidad, la innovación». Y más adelante, impugnando la figura del intelectual universal añade: «Digamos que los intelectuales ya no tienen el papel de decir lo que es bueno. Depende de las propias personas, basando su juicio en los diversos análisis de la realidad que se les ofrecen, en cómo trabajar o comportarse espontáneamente, de modo que puedan definir por sí mismas lo que es bueno para ellas. Lo que es bueno, es algo que viene a través de la innovación. El bien no existe, así, en un cielo atemporal, con gentes que vendrían a ser como los astrólogos del bien, cuyo trabajo sería determinar cuál es la naturaleza favorable de las estrellas. El bien lo definimos nosotros, lo practicamos, lo inventamos. Y esto es un trabajo colectivo». Véase, Foucault, M., «Power, Moral Values, and the Intellectual».

6 Véase al respecto, por ejemplo: «La valeur d'usage de D.A.F. de Sade» (1) y (2); en CEuvres complètes, II, Gallimard, París 1970, pp. 54-69 y 70-72, respectivamente.

7 Detienne, M., Les mâ̂tres de la vérité dans la Grèce archaïque, 1967, trad. Juan José Herrera, Ed. Taurus, Madrid 1981. 
Si intentáramos construir paso a paso, de un modo didáctico, las articulaciones mayores que componen esta figura, probablemente un modo amable de establecer un punto de partida podría ser situarse en el verano de 1967, en plena resaca por el escándalo suscitado a raíz de la publicación de Las palabras y las cosas un año antes, en el punto álgido del llamado boom estructuralista. Foucault acaba de ser mediáticamente consagrado como el filósofo del movimiento estructuralista (su presunto «intelectual universal», portavoz de la nueva visión del mundo), uno de los cuatro «salvajes» de la célebre caricatura de Maurice Henry, junto a Cl. Lévi-Strauss (el etnólogo y patriarca del movimiento), J. Lacan (el psicoanalista) y R. Barthes (el semiólogo), caricatura que acabó por convertirse en el emblema paródico del boom. Foucault hace lo que puede por desmarcarse a cualquier precio de la avalancha mediática que amenaza con desnaturalizar la recepción de su trabajo: en primer lugar, huye de París, solicita y obtiene una cátedra de Filosofía en Túnez, para los próximos tres años. Y luego, se enfrenta violentamente con el rol de filósofo que se le ha impuesto y va más allá, hasta poner en cuestión la vigencia de la filosofía misma, tal como es entendida en los medios académicos. Y hay que destacar que, en esa problematización de la filosofía se produce ya una primera elaboración de lo que será la distinción entre el intelectual universal y el intelectual específico. Recordemos sus palabras, en dos pasos. A principios del verano de 1967 respondía así en una entrevista: «Me parece que la filosofía hoy ya no existe, no que haya desaparecido, sino que se ha diseminado en una gran cantidad de actividades diversas: así las actividades del axiomático, del lingüista, del etnólogo, del historiador, del revolucionario, del hombre político pueden ser formas de actividad filosófica. En el siglo XIX era filosófica la reflexión que se interrogaba sobre las condiciones de posibilidad de los objetos, hoy es filosófica toda actividad que hace aparecer un objeto nuevo para el conocimiento o la práctica - se corresponda esta actividad con las matemáticas, la lingüística, la etnología o la historia» ${ }^{8}$. Declaraciones éstas que todavía consuenan perfectamente con el talante que comenzaba a ser reconocido bajo el rótulo de "estructuralismo» (del que Foucault se está desmarcando explícita e insistentemente, a pesar de que en su momento pensara como subtítulo para Las palabras y las cosas: Una arqueología del estructuralismo; en lugar del definitivo: Una arqueología de las ciencias humanas). Sin embargo, a finales de verano de aquel mismo año, nos encontraremos con la sorpresa de ver a Foucault asumiendo plenamente el rol de filósofo del que hace solo unos meses trataba de distanciarse, y precisando además en qué sentido el nombre le convenía. «Que lo que hago tenga algo que ver con la filosofía, es muy posible, sobre todo en la medida en que, por lo menos desde Nietzsche, la filosofía tiene como tarea diagnosticar y ya no trata

8 Foucault, M., «Sur les façons d'écrire l'histoire» (entrevista con R. Bellour), en: Les Lettres françaises, $\mathrm{n}^{\circ} 1187,15-21$ de junio de 1967, pp. 6-9 ; recogido en Foucault, M., DE I, $\S 48$, p. 597. 
de decir una verdad que pueda valer para todos y para siempre. Yo trato de diagnosticar, de realizar un diagnóstico del presente: decir lo que somos hoy y lo que significa, hoy, decir lo que decimos. Este trabajo de excavación bajo nuestros pies caracteriza desde Nietzsche al pensamiento contemporáneo, y es en este sentido que puedo declararme filósofo»" ${ }^{9}$. Actividad de diagnóstico del presente, y crítica de la verdad entendida como algo que puede valer para todos y para siempre, es decir, reivindicación del trabajo específico del intelectual e impugnación del «intelectual universal» y la ficción ecuménica de una verdad universal sobre la que se sostenía. Pero también hay en lo dicho una clara anticipación de los tres principios de su moral antes citados, el rechazo a cualquier verdad universal, la curiosidad por lo que significa, hoy, decir lo que decimos, y el diagnóstico del presente, en la forma de una innovación posible.

Podría decirse que esta primera caracterización del gesto filosófico por el cual Foucault se reconoce como filósofo (evocando además el padrinazgo de Nietzsche) venía a ser como un primer paso, un soporte desde el cual los mecanismos de aprobación/desaprobación puestos en obra por Foucault comenzaban a ser inteligibles, y también discutibles por tanto, jugándolos sobre los ejemplos concretos que los diferentes colectivos extraían de sus ámbitos respectivos. Conforme avanzaban las discusiones, el obstáculo que oponía la creencia en una verdad universal (o en la validez indiscutible de los universales antropológicos) venía a doblarse frecuentemente con el peso muerto que sobre las discusiones ejercía una cierta filosofía de la historia, entendida como el despliegue de la verdad universal a lo largo del tiempo. Era entonces el momento de detenerse en la cláusula por medio de la cual la historia queda entendida como una forma de etnología interna a nuestra propia cultura (último capítulo de Las palabras y las cosas), y que en tanto que tal, su primera obligación es conservar un principio de extrañeza frente al campo que estudia, cuidándose de no caer en ninguna forma de etnocentrismo. Era el momento de tratar de hacer entender que así como el etnólogo para llegar a conocer las comunidades que estudia debe evitar reconocerse en ellas y entenderlas como un ejemplo detenido en el tiempo de nuestra propia evolución cultural, el historiador para conocer el pasado debe evitar reconocerse en él, y dejar de entenderlo como un escalón que conduce a nuestro propio presente ${ }^{10}$.

9 Foucault, M., «Che cos’è lei Professor Foucault?» (entrevista con P. Caruso), La Fiera letteraria, n $^{\circ}$ 39, 28 de septiembre de 1967, pp. 11-15; recogido en: FoucAulT, M., DE I, § 50, p. 606. La contraposición que propongo entre estas dos afirmaciones se justifica tan solo por su virtud didáctica, no se pretende sugerir una evolución (y menos aún algo como una retractación) en el pensamiento de Foucault. A pesar de la proximidad en la fecha de publicación de ambas declaraciones, hay que tener presente también que la primera se publica en París y la segunda en Milán, y son bien sabidas las diferencias entre el modo de presentar su pensamiento en París y en el extranjero (los casos más espectaculares, sus entrevistas en Japón o en EE.UU.).

10 Como ilustración de esta cláusula, he usado repetidamente el recurso de acudir al primer aforismo de Aurora («Nachträgliche Vernünftigkeit»), de NiETzsche: «Todas las cosas que duran mucho tiempo se van impregnando poco a poco y hasta tal punto de racionalidad 
Evidentemente, el hábito de pensar en términos de verdad universal y la comprensión de la historia consiguiente son hábitos tenaces que en ningún modo se pretendía impugnar. Pero para lograr que fuera posible un diálogo efectivo entre el trabajo de Foucault y las preocupaciones teóricas y políticas de un determinado colectivo, era preciso el reconocimiento del peso que determinadas verdades universales ejercían en tal o cual planteamiento concreto, y en un segundo momento, que se aceptara suspender metódicamente su mandato y se probara a seguir razonando fuera de sus límites. Para que el diálogo fuera fructífero era preciso que el interlocutor aceptara salir a la exterioridad, asumiendo un coeficiente de extrañeza, fuera del imperio de lo obvio. $\mathrm{O}$ dicho de otro modo, que no había que relacionarse con el discurso de Foucault como si en éste se encontrara la formulación de algún tipo de verdad universal, sino que había que usarlo como un revelador del juego de relaciones complejas que aparecen en un dominio dado cuando se suspende la verdad universal que lo legitima. Lo que en definitiva esta primera aparición de la figura del in/moralista debía dejar claro es que en Foucault no se encuentra la doctrina de una visión del mundo a la que haya que convertirse, pero sí una buena colección de herramientas locales con las que problematizar inercias, cuestionar legitimaciones, y despertar la curiosidad ${ }^{11}$. Un primer paso, mínimo todavía, pero decisivo.

\section{III}

A partir de esta primera experiencia del pensamiento de Foucault como algo que es efectivamente pensable, es decir atendible y plausible, la figura del in/moralista podía encontrar entonces un segundo lugar en el que mostrar algo más su juego, en la primera partición problematizada por Foucault, el par razón/ locura. Hay que imaginar su gesto (levantándose contra el murmullo generalizado que dice que las cosas son lo que deben ser y están como deben estar, e impugnando

que llega a ser inverosímil que procedan de la irracionalidad. Cabe decir que no hay historia de una génesis [Entstehung] que no impresione el sentir como algo paradójico y sacrílego [paradox und frevelhaft]. ¿En qué se ocupa constantemente el historiador, sino en contradecir [Widerspricht]?».

11 Podría ser de utilidad aquí tener presente la advertencia que realizaba Foucault en su defensa cátedra en el Collège de France (Titres et Travaux, Paris 1969; folleto sin mención editorial; recogido en Foucault, M., DE I, § 71, pp. 842 y ss.): «En la medida en que, en una época dada, existen formas y dominios bien específicos, pueden descomponerse en varios sistemas de pensamiento. Está claro, no se trata en ningún modo de determinar el sistema de pensamiento de una época definida, o algo así como su "visión del mundo", se trata por el contrario de fijarse en los diferentes conjuntos cada uno de los cuales lleva un tipo de saber muy particular, que une unos comportamientos, con unas reglas de conducta, unas leyes, unas costumbres o unas prescripciones; que forman así unas configuraciones estables y a la vez susceptibles de transformación. También, se trata de definir entre estos diferentes dominios relaciones de conflicto, de vecindad o de intercambio. Los sistemas de pensamiento son las formas en las que, en una época dada, los saberes se singularizan, encuentran su equilibrio y entran en comunicación». 
el acomodo en sí mismos del saber y las instituciones), cuando pregunta: «¿cómo ha llegado nuestra cultura a dar a la enfermedad el sentido de la desviación, y al enfermo un estatuto que lo excluye? ¿Y cómo, a pesar de esto, nuestra sociedad se expresa en estas formas mórbidas en las que se niega reconocerse? $\gg^{12}$. Foucault formula estas preguntas en los tiempos en que es profesor ayudante de psicología en Lille, y está muy interesado por el análisis existencial de Binswanger - y la lección del psiquiatra suizo resuena en el modo de plantearlas. En lugar de encarar la cuestión de si las cosas son o no lo que deben ser, Foucault da un rodeo: si entendemos por cultura un cierto equilibrio en su orden simbólico entre unas formas de expresión y unos modos de reconocimiento, ¿cómo entender la negativa a reconocer las formas en las que la locura se expresa? Así, la carga del contraargumento a la partición razón/locura será precisamente una evidencia simple: la excelencia cultural irrenunciable de ciertas obras susceptibles de ser calificadas como «de locura». Años más tarde, su tesis doctoral, Historia de la locura terminará con unas palabras que insisten en el mismo gesto: «Astucia y nuevo triunfo de la locura: este mundo, que creía medirla y justificarla por la psicología, debe justificarse ante ella, puesto que en sus esfuerzos y en sus debates, él se mide con la desmesura de obras como la de Nietzsche, Van Gogh, o Artaud. Y nada en él, sobre todo no lo que puede conocer de la locura, le garantiza que esas obras de locura lo justifican ${ }^{13}$. Y también aquí es Nietzsche el pivote que posibilita la torsión del punto de vista en el plano de lo pensable. Como lo será, y de un modo programático, de nuevo en el texto que acompañaba a su tesis doctoral, la tesis complementaría sobre la Antropología de Kant: «¿No sería posible concebir una crítica de la finitud que fuera liberadora tanto respecto al hombre como con respecto a lo infinito y que mostrara que la finitud no es término, sino esta curvatura y este nudo del tiempo en los que el final es el comienzo? La trayectoria de la pregunta: Was ist der Mensch en el campo de la filosofía se acaba en la respuesta que la recusa y la desarma: der Übermensch» ${ }^{14}$.

12 Foucault, M., Maladie mentale et personnalité, P.U.F., Paris 1954, p. 75.

13 Foucault, M., Folie et déraison. Histoire de la folie à l'âge classique, Plon, París 1961, p. 663.

14 Foucault, M., Introduction à l'Anthropologie, Vrin, París 2008, pp. 78-79. Años más tarde, en Japón, Foucault relataría pacientemente el origen de su interés por la locura en estos términos: "Lo que los etnólogos hicieron con las sociedades — este intento de explicar tanto los fenómenos negativos como los positivos- me pregunto si no podría aplicarse a la historia de las ideas.... ¿Cuáles son las ideas, o cuáles son los comportamientos, o cuáles son las conductas, o cuáles son los principios legales o morales que no se aceptan, que no se pueden aceptar, que están excluidos del sistema? Fue de este modo como me interesé en el problema de la locura. La locura, en una sociedad como la nuestra, y de hecho creo que en cualquier sociedad, es evidentemente lo que ante todo está excluido. Me pregunto si no podríamos estudiar el racionalismo clásico o, más generalmente, el sistema de racionalidad de nuestras sociedades, de las sociedades que nos son contemporáneas, si no podríamos examinar, analizar este sistema de racionalidad estudiando, al mismo tiempo que el sistema de racionalidad positiva, el sistema de exclusión negativa. ¿Qué forma de locura se excluye? ¿Cómo excluimos la locura? ¿Cómo dividimos y trazamos una línea entre la razón y la locura? Quizás es colocándose precisamente en este eje del límite, en esta frontera, en ese filo 
Hay que añadir que, mirado al trasluz, el alambre último que sostiene el alegato de Historia de la locura dibuja ya claramente el gesto del in/moralista, los tres pasos que le hemos atribuido: el rechazo (a la locura entendida como una verdad universal que se despliega en la historia: la locura-enfermedad mental es un invento reciente); la curiosidad (por cada uno de los detalles de la génesis de esta pretendida verdad universal: las condiciones de posibilidad que permitieron la invención); la innovación: «quizá llegue un día en que no se sepa ya bien lo que ha podido ser la locura.... ${ }^{15}$. Encontraremos estos tres pasos en adelante en casi todos sus libros publicados en vida: (1) denuncia del objeto que se estudia (la enfermedad, el hombre, la sexualidad...) como un invento reciente; (2) indagación al detalle de las condiciones de posibilidad del invento, discursivas e institucionales; (3) anuncio de la plausibilidad de una caducidad del invento, en cuanto sus condiciones de posibilidad sufran una modificación suficiente. Desde la perspectiva del in/moralista es este último punto el que le afecta especialmente, no evidentemente en cuanto profecía sobre nuestro futuro, pero sí por la torsión de perspectiva que implica. Asumir como plausible la caducidad de alguna de nuestras verdades universales conlleva la posibilidad de colocar el punto de subjetivación en ese futuro en el que ya han caducado y cabe dirigir desde él una mirada a nuestro presente. O dicho de otro modo, implica asumir (aplicando la crítica del etnocentrismo a la propia cultura histórica europea) que «todo lo que se piensa será pensado de nuevo por un pensamiento que todavía no ha salido a luz ${ }^{16}$, y seguir pensando a partir de ahí. Nietzsche le puso nombre a esa torsión de la mirada, la llamó contemplación intempestiva (unzeitgemäße Betrachtung), y la atribuyó al Versucher, aquella figura cuyo pensamiento se caracteriza por ser tentativa y tentación... ${ }^{17}$

de cuchillo entre la razón y la locura, entre la locura y la no-locura, que seremos capaces de comprender tanto lo que es reconocido y aceptado positivamente por una sociedad como lo que es excluido y rechazado por esta misma sociedad, por esta misma cultura. Esta es la perspectiva, un poco etnológica, que me gustaría aplicar a la historia de las ideas. Digo "etnológica" en la medida en que se trataría de aplicar a la historia de las ideas un método, una forma de análisis de sistemas que ya ha tenido éxito en el orden de la etnología». Véase «Kuôki to shakai [La locura y la sociedad]», en: Foucault, M., DE III, § 222.

15 Con estas palabras comienza «La folie, l'absence d'œuvre» (La Table ronde, $\mathrm{n}^{\circ}$ 196: Situation de la psychiatrie, mayo de 1964; recogido en Foucault, M., DE, I, § 25), reeditada como apéndice a la edición de 1972 de la Historia de la locura, junto con su respuesta a J. DERRIDA: «Mon corps, ce papier, ce feu» (Foucault, M., DE II, § 102), texto del que había una primera versión, «Derrida e no kaino», publicada por la revista japonesa Paideia (Foucault, M., DE II, § 104),

${ }_{16}$ Foucault, M., Les mots et les choses, Gallimard, París 1966, p. 383. Véase en especial todo el parágrafo «La historia», del último capítulo.

17 Sobre la figura del Versucher, véase mi Vidas de Nietzsche, Alianza, Madrid 2018, pp. 197 y ss. De entre las numerosas muestras que encontramos en Foucault de esta contemplación intempestiva, el más bello ejemplo, con unas resonancias profundamente nietzscheanas, nos lo brinda al final del volumen primero de su historia de la sexualidad, donde dice (y ruego que se atienda al juego de los tiempos verbales): «Tal vez un día se sorprenderán. Se comprenderá mal que una civilización tan claramente consagrada al desarrollo de inmensos aparatos 
Es sin duda la instauración de la ratio cartesiana lo que le posibilita de entrada esta extensión del ámbito afectado por la partición razón/locura, del espacio estrictamente clínico a la forma misma de la racionalidad moderna propia al pensamiento occidental, pero es el pensamiento de Nietzsche el que le permite pensar esta extensión en toda su radicalidad. Es una evidencia que la figura del in/moralista cojearía gravemente si se dejara de retener la lección nietzscheana, aunque al hacerlo tenga lugar un cambio de plano, por el que el pensamiento pasa a plegarse sobre sí mismo y se pone en cuestión. Aparentemente, la presencia de Nietzsche en sus primeros escritos pasa a un segundo plano rápidamente, aunque en realidad sigue un curso subterráneo en sus textos de crítica literaria a lo largo de los años sesenta, transcurre a través de Bataille, de Blanchot, de Klossowski, aparece como una presencia gloriosa en su reseña sobre el teatro filosófico de Deleuze... Finalmente, durante un breve lapso, a principios de los años setenta, parece pasar a ocupar toda su actividad de pensamiento, destacando muy especialmente tres documentos: la publicación de «Nietzsche, la genealogía, la historia», en homenaje a Jean Hyppolite, en 1971; la conferencia de abril del mismo año en la Universidad McGill de Montreal, «Leçon sur Nietzsche : Comment penser l'histoire de la vérité avec Nietzsche sans s'appuyer sur la vérité»; y finalmente, del 21 al 25 de mayo de 1973, las sesiones en Rio de Janeiro que dieron lugar a $A$ verdade e as formas jurídicas ${ }^{18}$.

Si hubiera que escoger un solo fragmento de estos escritos que diera ejemplo preciso de la incorporación que hace Foucault del pensamiento nietzscheano, en lo que atañe a la figura del in/moralista, apostaría por una argumentación de su «Lección sobre Nietzsche», que nos lo muestra desglosando el gesto mismo por el que se acaba con toda posible moral del conocimiento (me he permitido el énfasis de numerar los puntos):

(1) El conocimiento es una invención detrás de la cual hay otra cosa muy diferente: un juego de instintos, impulsos, deseos, miedo, voluntad de apropiación. Sobre esta escena en la que combaten se produce el conocimiento; (2) se produce no como efecto de su armonía, de su feliz equilibrio, sino de su odio, de su compromiso dudoso y provisional, de un pacto frágil que siempre están dispuestos a traicionar. No es una facultad permanente, es un acontecimiento o al menos una serie de acontecimientos; (3) es siempre siervo, dependiente, interesado (no en sí mismo, sino en lo que es susceptible de interesar al

de producción y de destrucción haya encontrado el tiempo y la infinita paciencia como para interrogarse con tanta ansiedad sobre lo que tiene que ver con el sexo; sonreirán tal vez recordando que esos hombres que fuimos creían que por ese lado existía una verdad por lo menos tan preciosa como la que antes habían pedido a la tierra, a las estrellas y a las formas puras de su pensamiento». Foucault, M., La volonté de savoir, Gallimard, París 1976, p. 208.

18 Las referencias son, respectivamente: Hommage à Jean Hyppolite, PUF, Paris 1971, véase Foucault, M., DE II, § 84; la última de las Leçons sur la volonté de savoir (Collège de France, 1970-71), Gallimard/Seuil, París 2011; y para las conferencias de Río, véase Foucault, M., DE II, § 139. 
instinto o los instintos que lo dominan); (4) y si se da como conocimiento de la verdad, es porque produce la verdad gracias al juego de una falsificación primera y siempre prorrogada que pone la distinción entre lo verdadero y lo falso ${ }^{19}$.

\section{IV}

En cierta medida los tres principios de moral que Foucault defendía, el rechazo, la curiosidad y la innovación, pueden ser entendidos como gestos que ponen en cuestión el límite impuesto por lo incuestionable, lo obvio y lo impensable en un dominio dado («...never to accept anything as definitive, untouchable, obvious, or immobile» — decía Foucault en el lema que encabeza estas páginas), como una reivindicación de la transgresión constante de dichos límites. Y aunque sea en esta medida, hay que añadir un último rasgo a esta figura del in/moralista antes de permitir que vuele sola, porque la noción de transgresión parece convenir singularmente bien a la dinámica del pensamiento de Foucault, si se la imagina operando en una multiplicidad de escalas y niveles. Las primeras formulaciones explícitas de la noción tienen lugar en la época en que incuba el pensamiento nietzscheano en el ámbito literario, y sin duda la más relevante será la dedicada a Bataille en el texto «Préface à la transgression $»^{20}$. Allí la transgresión queda caracterizada como el gesto que se corresponde con una experiencia constante de la muerte de Dios; es el que responde a esa precisa experiencia, acentuada como constante. Pero contrariamente al automatismo que empuja a emparejar transgresión con negación o contradicción, Foucault defiende su carácter afirmativo, su estatuto de afirmación no positiva, «una afirmación que no afirma nada, en plena ruptura de transitividad». Y el halo paradójico que parece envolver a la expresión «transgresión afirmativa» (o afirmación no positiva) se compenetra bien con la barra que espaciaba nuestra denominación del in/moralista, como impidiendo que se estabilizara en uno u otro polo. Como parece igualmente convenirle la caracterización de la dinámica de la transgresión que allí se lleva a cabo. «La transgresión no niega el límite porque, si lo negase, ella misma no sería posible; mejor aún, no afirma el límite sin afirmar al mismo tiempo ese ilimitado sin el que no tendría lugar alguno al que dirigirse ${ }^{21}$.

El componente insurreccional que viene asociado con la noción de transgresión se mantiene explícito todo a lo largo de su ciclo literario, pero no mucho más allá. En la clase del 3 de enero de 1973 del curso La société punitive,

19 Foucault, M., Leçons sur la volonté de savoir, pp. 219-20.

20 «Préface à la transgression», en: Critique, no 195-196: Hommage à G. Bataille, 1963; en Foucault, M., DE I, § 13.

21 Véase al respecto el pormenorizado análisis que lleva a cabo Antonio Castilla de la noción de transgresión en el ciclo literario de Foucault, en CASTILLA, A., Una Extraña Triangulación: Lenguaje, obra y literatura en Michel Foucault, Comares, Granada 2020. 
Foucault explica que «la noción de transgresión jugó durante un período de tiempo [un papel] más o menos comparable a [la noción de] exclusión. También ella permitió una especie de inversión crítica, que es importante porque posibilitó eludir conceptos como la anomalía, la culpa y la ley. Permitió una inversión de lo negativo a lo positivo, y de lo positivo a lo negativo. Permitió ordenar todas estas nociones no ya según la mayor, la ley, sino según el límite». Pero a continuación pasa a desestimarla como útil de análisis en la medida en que «sigue ordenada por el sistema general de las representaciones contra las que se dirige $»^{22}$.

Suele atribuirse al descrédito que se sigue de este juicio el que la noción de transgresión desaparezca de su léxico, a partir de entonces. Sin embargo, este hecho no debería llevarnos a una retractación de lo afirmado antes, respecto de su profunda congruencia con la figura del in/moralista. Y es que, aunque bajo otra formulación, la dinámica cognoscitiva, ética y política que nombraba la noción de transgresión va a continuar una fluencia subterránea hasta el fin de sus días. La lección de Bataille, el gesto de ponerse en juego en el límite, seguirá estando viva aunque ahora sea otro su modo de situarse en el discurso. Valga como prueba, el siguiente ejemplo, posterior en cinco años a su supuesta retractación: «Todo aquello de lo que me he ocupado hasta ahora tiene que ver, en el fondo, con el modo en que, en las sociedades occidentales, las personas han llevado a cabo estas experiencias, fundamentales sin duda, que consisten en entrar en un proceso de conocimiento de un dominio de objetos, a la vez que se constituyen ellas mismas como sujetos con un estatus fijo y determinado. Por ejemplo, conocer la locura constituyéndose a sí mismo como sujeto razonable; conocer la enfermedad constituyéndose a sí mismo como sujeto vivo; o la economía constituyéndose a sí mismo como sujeto de trabajo; o el individuo conociéndose a sí mismo según una cierta relación con la ley.... Así que siempre existe este compromiso con uno mismo dentro del propio conocimiento. En particular, me he esforzado por comprender cómo el hombre ha transformado algunas de estas experiencias límite en objetos de conocimiento: locura, muerte, crimen. Aquí es donde encontramos temas de Georges Bataille, pero retomados en una historia colectiva que es la de Occidente y su conocimiento. Siempre es una cuestión de experiencia limite y de historia de la verdad» ${ }^{23}$.

22 La société punitive. Collège de France. 1972-73, EHESS, Gallimard, Seuil, París 2013, p. 7. En nota al pie se nos informa de la siguiente anotación manuscrita de Foucault: «Hablar de transgresión no es referirse a la transición de lo lícito a lo ilícito (más allá de lo prohibido): es referirse a la transición al límite, más allá del límite, a lo que está sin reglas, y por lo tanto sin representación».

23 «Conversazione con Michel Foucault», D. Trombadori (finales de 1978), Il Contributo, año 4, nº 1, 1980; DE IV, § 281 
En el «Préface à la transgression», Foucault conjeturaba que tal vez el descubrimiento de la afirmación no positiva (la prueba del límite) llegara a representar para el pensamiento contemporáneo algo semejante a lo que la apertura del pensamiento crítico por Kant significó para el pensamiento moderno ${ }^{24}$. Al final del camino, en su último año de vida, será también Kant la referencia que le permite dibujar una nueva figura de la transgresión, nombrada ahora franqueamiento [franchissement $]^{25}$. Y lo hace con un alegato magnífico que constituye un inmejorable retrato en vivo de lo que aquí se ha llamado la figura del in/moralista. «Evidentemente hay que dar un contenido más positivo a lo que puede ser un êthos filosófico consistente en una crítica de lo que decimos, pensamos y hacemos, a través de una ontología histórica de nosotros mismos. Este êthos filosófico puede caracterizarse como una actitud límite. No se trata de un comportamiento de rechazo. Hay que escapar a la alternativa del dentro o fuera, hay que estar en las fronteras. La crítica es el análisis de los límites y la reflexión sobre ellos. Pero si la cuestión kantiana era saber qué límites el conocimiento debía renunciar a franquear, me parece que hoy la cuestión crítica debe plantearse en términos positivos: en lo que se nos presenta como universal, necesario, obligatorio ¿cuál es la parte de lo singular, contingente y debido a obligaciones arbitrarias? Se trata en suma de transformar la crítica ejercida

24 «Tal vez la filosofía contemporánea ha inaugurado, descubriendo la posibilidad de una afirmación no positiva, un desfase [décalage] cuyo único equivalente se encontraría en la distinción hecha por Kant entre el nihil negativum y el nihil privativum - distinción que, como se sabe, abrió el camino del pensamiento crítico. Esta filosofía de la afirmación no positiva, es decir de la prueba del límite, es la que, según creo, Blanchot definió como principio de la impugnación [contestation]. No se trata de una negación generalizada, sino de una afirmación que no afirma nada: en plena ruptura de transitividad. La impugnación no es el esfuerzo del pensamiento por negar unas existencias o unos valores, es el gesto que reconduce a cada uno de ellos a sus límites, y por ello al Límite en el que se cumple la decisión ontológica: impugnar es ir hasta el corazón vacío donde el ser alcanza su límite y donde el límite define el ser. Ahí, en el límite transgredido, resuena el sí de la impugnación, que deja sin eco al I-A del asno nietzscheano», Foucault, M., DE I, § 13, p. 238.

25 No cabe sin embargo contraponer conceptualmente ambos términos, más bien al contrario. Encontramos bastantes indicios de que Foucault los entiende como sinónimos. Un ejemplo, extraído de uno de los primeros textos de su ciclo literario: «El lenguaje que prescribe a una obra su espacio, su estructura formal y su existencia misma como obra de lenguaje, puede conferir al lenguaje segundo que reside en el interior de la obra, una analogía estructural con el delirio. Hay que distinguir: el lenguaje de la obra es, más allá de sí misma, aquello hacia lo que se dirige, lo que dice; pero es también, más acá de sí misma, aquello a partir de lo cual habla. A este lenguaje no se le pueden aplicar las categorías de normal y patológico, de la locura y el delirio; pues es franqueamiento [franchissement] primero, pura transgresión [transgression]». Véase "Introduction», en: J.-J. Rousseau, Rousseau juge de Jean-Jacques. Dialogues, A. Colin, Paris 1962; Foucault, M., DE I, § 7. El término es relativamente frecuente mientras Foucault escribe sobre literatura, pero al igual que transgression, franchissement desaparece prácticamente de su léxico poco después, para reaparecer precisamente con esta ocasión. 
en la forma de la limitación necesaria en una crítica práctica en la forma del franqueamiento posible». Y en la recapitulación final de lo dicho, insiste: «Por lo tanto, caracterizaré el êthos filosófico propio de la ontología crítica de nosotros mismos como una prueba histórico-práctica de los límites que podemos cruzar, y por lo tanto como un trabajo de nosotros mismos sobre nosotros mismos como seres libres» ${ }^{26}$.

Después de estas palabras, a este intento de presentar la pertinencia de la figura del in/moralista como vía de acceso a la inteligibilidad del trabajo de Foucault, no le queda sino la rúbrica; dejar constancia de un encuentro, esta vez en el viejo Centre Michel Foucault, cuando todavía se hospedaba en la Bibliothèque du Saulchoir. Tengo ante mí el pliego de notas manuscritas que Foucault fue tomando en el curso de sus conversaciones con H. Dreyfus y P. Rabinow, en Berkeley, en abril de 1983. Y de pronto, en lo alto de uno de los folios, en una esquina y como presidiendo la página, una escueta anotación al margen, bien resaltada: «El objetivo es: la creación de libertad» ${ }^{27}$.

Pienso que la figura del in/moralista es la figura de alguien para quien la libertad es siempre y ante todo lo primero, el norte; pienso que sin ella no existe vida del conocimiento ni vida moral ninguna ni la vida política tampoco. Me pregunto si tal vez podría decirse que para el in/moralista la libertad y la vida nombran lo mismo.

Universidad de Barcelona

Miguel Morey

morey@telefonica.net

[Artículo aprobado para publicación en febrero de 2020]

26 Y a continuación aclara: «Es cierto que debemos renunciar a la esperanza de no tener nunca acceso a un punto de vista que nos permita acceder a un conocimiento completo y definitivo de lo que puede constituir nuestros límites históricos. Y, desde este punto de vista, la experiencia teórica y práctica que hacemos de nuestros límites y de su posible cruce es siempre en sí misma limitada, determinada y, por tanto, a replantear. Pero eso no significa que cualquier trabajo sólo se puede hacer en desorden y contingencia. Esta obra tiene su generalidad, su carácter sistemático, su homogeneidad y su envite [enjeu]». «What is Enligthenment?» en: Paul Rabinow (ed.), The Foucault Reader, Pantheon Books, New York 1984; Foucault, M., DE IV, § 339.

27 La anotación corresponde probablemente a la sesión del 26 de abril de 1983 [Centre Michel Foucault, documento D-250(12)/942.1988]. La transcripción de dichas conversaciones se recoge en Hubert L. Dreyfus and Paul Rabinow, Michel Foucault: Beyond Structuralism and Hermeneutics, University of Chicago Press, 1983²; en los anexos. 